\title{
Lasting s-ketamine block of spreading depolarizations in subarachnoid hemorrhage: a retrospective cohort study
}

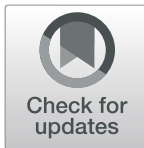

Edgar Santos $^{1 *}$ D, Arturo Olivares-Rivera', Sebastian Major ${ }^{2,3,4}$, Renán Sánchez-Porras ${ }^{1}$, Lorenz Uhlmann", Kevin Kunzmann", Roland Zerelles', Modar Kentar', Vasilis Kola, Adrian Hernández Aguilera', Mildred Gutierrez Herrera', Coline L. Lemale ${ }^{4}$, Johannes Woitzik ${ }^{6}$, Jed A. Hartings ${ }^{7,8}$, Oliver W. Sakowitz ${ }^{1,9}$, Andreas W. Unterberg ${ }^{1}$ and Jens P. Dreier $2,3,4,10,11$ (D)

\begin{abstract}
Objective: Spreading depolarizations (SD) are characterized by breakdown of transmembrane ion gradients and excitotoxicity. Experimentally, N-methyl-D-aspartate receptor (NMDAR) antagonists block a majority of SDs. In many hospitals, the NMDAR antagonist s-ketamine and the GABA $A_{A}$ agonist midazolam represent the current second-line combination treatment to sedate patients with devastating cerebral injuries. A pressing clinical question is whether this option should become first-line in sedation-requiring individuals in whom SDs are detected, yet the s-ketamine dose necessary to adequately inhibit SDs is unknown. Moreover, use-dependent tolerance could be a problem for SD inhibition in the clinic.

Methods: We performed a retrospective cohort study of 66 patients with aneurysmal subarachnoid hemorrhage (aSAH) from a prospectively collected database. Thirty-three of 66 patients received s-ketamine during electrocorticographic neuromonitoring of SDs in neurointensive care. The decision to give s-ketamine was dependent on the need for stronger sedation, so it was expected that patients receiving s-ketamine would have a worse clinical outcome.

Results: S-ketamine application started $4.2 \pm 3.5$ days after aSAH. The mean dose was $2.8 \pm 1.4 \mathrm{mg} / \mathrm{kg}$ body weight $(\mathrm{BW}) / \mathrm{h}$ and thus higher than the dose recommended for sedation. First, patients were divided according to whether they received s-ketamine at any time or not. No significant difference in SD counts was found between groups (negative binomial model using the SD count per patient as outcome variable, $p=0.288$ ). This most likely resulted from the fact that 368 SDs had already occurred in the s-ketamine group before s-ketamine was given. However, in patients receiving s-ketamine, we found a significant decrease in SD incidence when s-ketamine was started (Poisson model with a random intercept for patient, coefficient - 1.83 (95\% confidence intervals - 2.17; 1.50), $p<0.001$; logistic regression model, odds ratio (OR) $0.13(0.08 ; 0.19), p<0.001)$. Thereafter, data was further divided into low-dose $(0.1-2.0 \mathrm{mg} / \mathrm{kg} B W / \mathrm{h})$ and high-dose $(2.1-7.0 \mathrm{mg} / \mathrm{kg} / \mathrm{h})$ segments. High-dose s-ketamine resulted in further significant decrease in SD incidence (Poisson model, $-1.10(-1.71 ;-0.49), p<0.001$; logistic regression model, OR $0.33(0.17 ; 0.63), p<0.001)$. There was little evidence of SD tolerance to long-term s-ketamine sedation through 5 days.

(Continued on next page)
\end{abstract}

\footnotetext{
* Correspondence: dredgarsantos@hotmail.com

${ }^{1}$ Neurosurgery Department, Heidelberg University Hospital-

Ruprecht-Karls-Universität Heidelberg, Im Neuenheimer Feld 400, 69120

Heidelberg, Germany

Full list of author information is available at the end of the article
}

(c) The Author(s). 2019 Open Access This article is distributed under the terms of the Creative Commons Attribution 4.0 International License (http://creativecommons.org/licenses/by/4.0/), which permits unrestricted use, distribution, and reproduction in any medium, provided you give appropriate credit to the original author(s) and the source, provide a link to the Creative Commons license, and indicate if changes were made. The Creative Commons Public Domain Dedication waiver (http://creativecommons.org/publicdomain/zero/1.0/) applies to the data made available in this article, unless otherwise stated. 
(Continued from previous page)

Conclusions: These results provide a foundation for a multicenter, neuromonitoring-guided, proof-of-concept trial of ketamine and midazolam as a first-line sedative regime.

Keywords: Stroke, Subarachnoid hemorrhage, Electrocorticography, Neuromonitoring, Ketamine, Spreading depression

\section{Introduction}

Ischemic lesions contribute to poor outcome after aneurysmal subarachnoid hemorrhage (aSAH) [1, 2]. Spreading depolarization (SD) is a key mechanism of lesion development because it initiates the cytotoxic neuronal edema in various gray matter structures [3]. Accordingly, SDs after aSAH occur abundantly [4-6]. Terminal SD was recently recorded in patients who either died from circulatory arrest [7] or suffered brain death despite sustained circulatory function $[8,9]$ or developed neuroimaging-proven early or delayed ischemic strokes after aSAH in the recording area [10-13]. In the context of lesion progression, terminal SD was typically preceded by a temporal cluster of increasingly prolonged SDs that could start up to hours earlier, suggesting a spiraling trend toward increasing risk of injury [10]. By contrast, isolated SD in eloquent and metabolically intact tissue is the pathophysiological correlate of the harmless migraine aura [14, 15]. SD induces tone alterations in resistance vessels, causing either transient hyperemia (normal hemodynamic response) in healthy tissue or severe hypoperfusion (inverse hemodynamic response = spreading ischemia) in tissue at risk for injury [16-18]. Experimentally, spreading ischemia could be the sole cause of widespread cortical infarcts [19]. In patients, the full continuum from spreading hyperemia to ischemia has been observed in aSAH patients [5], and spreading ischemia was associated with neuroimaging-proven lesion progression [10].

$N$-Methyl-D-aspartate receptor (NMDAR) antagonists block SD in metabolically intact tissue [20] where SD is short-lasting and harmless [21]. By contrast, they progressively fail to do so under elevated baseline $\mathrm{K}^{+}$concentration [22] or in increasingly ischemic or hypoxic tissue [23-26] where SDs are progressively longerlasting and deleterious. However, an important aspect is that SD, which comes from metabolically intact tissue, can invade tissue where it triggers spreading ischemia $[10,18]$. Spreading ischemia then transforms metabolically still slightly disturbed tissue into severely disturbed tissue. NMDAR antagonists could thus prevent metabolic collapse, if they block the trigger, SD, that becomes terminal SD via the vicious circle of SD-induced vasoconstriction [27].

The NMDAR antagonist ketamine has been found to be associated with a reduction in SD occurrence in a mixed population of 60 patients with traumatic brain injury (TBI), 31 patients with aSAH, and 24 patients with malignant hemispheric stroke $[28,29]$. The first prospective controlled trial of ketamine for SD inhibition recently confirmed this result in 8 patients with TBI and 2 with aSAH $[30,31]$. Also, a case of spontaneous intracerebral hemorrhage has been reported in whom a cluster of SDs disappeared in response to ketamine and reappeared after discontinuation of ketamine [32]. In bedside-to-bench translation, results were further replicated in swine studies in which the active enantiomer, $\mathrm{S}(+)$ ketamine (s-ketamine), decreased the expansion, amplitude, and speed of SDs at a dosing of $2 \mathrm{mg} / \mathrm{kg}$ body weight (BW)/h. However, complete blockade of SDs in adequately perfused tissue was achieved only at a high dose of $4 \mathrm{mg} / \mathrm{kg} \mathrm{BW} / \mathrm{h}[33,34]$. This suggested that the assumed neuroprotective effect of sketamine essentially starts at a dose that is above the recommended range, yet is nonetheless administered to patients by neurointensivists in individual cases. Another ketamine problem, previously observed in rats, is the use-dependent development of tolerance [35]. To better understand ketamine treatment, here we retrospectively analyzed a cohort of $66 \mathrm{aSAH}$ patients from a prospectively collected database. We investigated (i) the dose-response relationship of sketamine to inhibition of SD occurrence, SD expansion, and amplitude, (ii) whether there is evidence of tolerance development, and (iii) whether s-ketamine affects intracranial (ICP) or mean arterial pressure (MAP).

\section{Materials and methods General}

Inclusion criteria were (i) age $\geq 18$ years, (ii) World Federation of Neurosurgical Societies scale (WFNS) grades I-V and a Glasgow Coma Score $\geq 4$, (iii) ruptured saccular aneurysm proven by computed tomography (CT)-angiography or digital subtraction angiography, and (iv) either surgical treatment of the aneurysm via craniotomy or, in coiled patients, burr hole trepanation for placement of a ventricular drain or oxygen sensor, which allows the simultaneous placement of a subdural electrode strip (Wyler, 5-mm diameter; Ad-Tech Medical, Racine, Wisconsin, USA) [5]. Exclusion criteria were bilaterally fixed and dilated pupils or other signs of imminent death, as well as a history of trauma/bleeding $\geq 5$ days before admission. Using these pre-specified criteria, we identified 32 patients from a prospectively collected database of the University of Heidelberg Department of Neurosurgery who had been consecutively recruited between September 2004 and March 2014. Nineteen of these had been treated with s- 
ketamine at some time point during the electrocorticography (ECoG) monitoring time. Additionally, we identified 33 consecutive patients from a prospectively collected database at Charité-Universitätsmedizin Berlin who had been recruited between April 2005 and March 2009 whereas 4 patients were excluded. In addition, one patient who received s-ketamine and was monitored October 2010 was added to this list. In total, 14 patients from Berlin had been treated with s-ketamine.

Figure 1 provides an electrode strip density map illustrating in a schematic fashion the typical locations of the subdural electrode strips in our patient population. The near-direct current (DC)/alternate current (AC)-ECoG was recorded in four, five, or seven active channels from either a six-contact or an eight-contact linear electrode array (interelectrode distance $1 \mathrm{~cm}$ ) with electrode contacts connected in sequential bipolar fashion to a GT205 amplifier (0.01-45 Hz) (ADInstruments, New South Wales, Australia) (Fig. 2). In some patients, contact 1 served as ground. In others, a subdermal platinum needle electrode was additionally placed over the hemisphere ipsilateral to the recording strip. Each contact of the recording strip was then referenced to the subdermal platinum electrode, allowing recordings in monopolar fashion in addition to the bipolar recordings (Fig. 3). Data were sampled at $200 \mathrm{~Hz}$ and recorded and analyzed with a Powerlab 16/SP analog/digital converter and Chart-7 software (ADInstruments, New South Wales, Australia). SDs were defined as recommended recently [37]. Accordingly, a cluster of recurrent SDs was defined by the occurrence of at least three SDs occurring within three or fewer consecutive recording hours. Further SDs were counted as clustered SDs when they occurred within less than $1 \mathrm{~h}$ after the previous SD.

The anesthesiologic standard procedures were nearly identical at both institutions. Notably, they were not influenced by data from the ECoG monitoring. While the aneurysm was secured, patients were deeply sedated using short-term sedatives and analgesics such as propofol, sevoflurane, remifentanil, and small amounts of sufentanyl. Thereafter, sedation was transiently reduced to create a time window for the assessment of the neurological status. If the patient presented with a new neurological deficit, a CT scan and optional control angiography were performed. Whenever possible, the patient was extubated within the first $6 \mathrm{~h}$ after the surgical or endovascular intervention. If this was not possible, the sedation was repeatedly reduced in regular time intervals over the next 1 to 3 days to create further windows for neurological assessment. If predicted from the amount of early brain damage and repeated neurological assessments that prompt recovery would be unlikely, long-term sedation was started using the sedative midazolam and the analgesics sufentanyl and fentanyl. S-ketamine was then usually added for clinical purposes to supplement midazolam, if (i) maximal doses of midazolam and sufentanyl were insufficient to reach adequate analgo-sedation, (ii) ICP continued to peak above the desired level, or (iii) ventilation was difficult. Barbiturates such as thiopental or methohexital were only rarely used and muscle relaxants were avoided. When

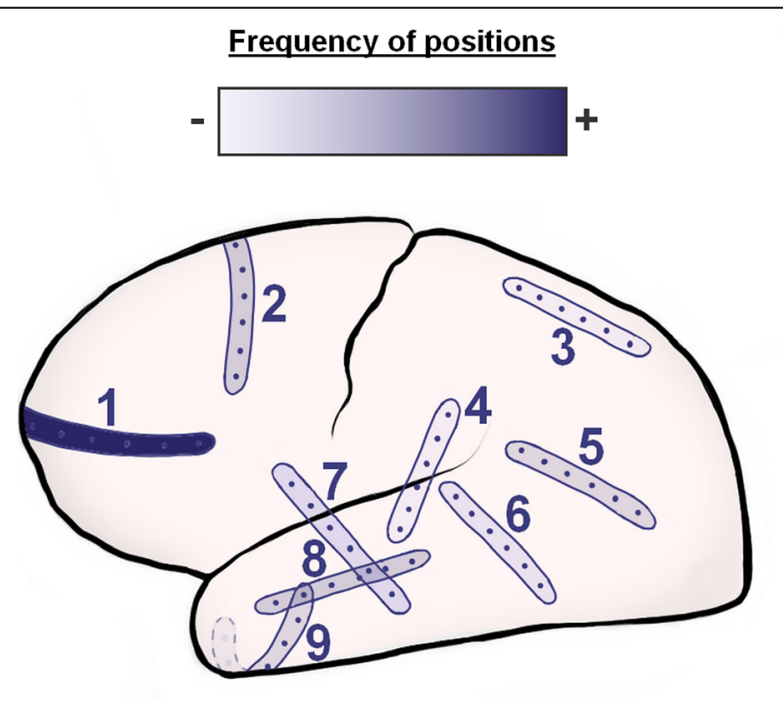

Percentage of occurrence

$1: 55 \%$

$2: 10 \%$

$3: 1.5 \%$

$4: 1.5 \%$

$5: 7 \%$

$6: 3 \%$

$7: 5 \%$

$8: 10 \%$

$9: 7 \%$

Lateralization of the strip

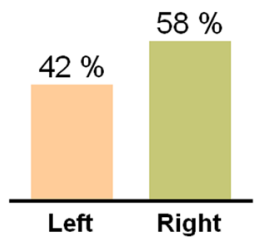

Fig. 1 Recording strip density map illustrating the frequency of different locations of the electrode strips in our patient population. The strip locations were taken from the CT topograms 


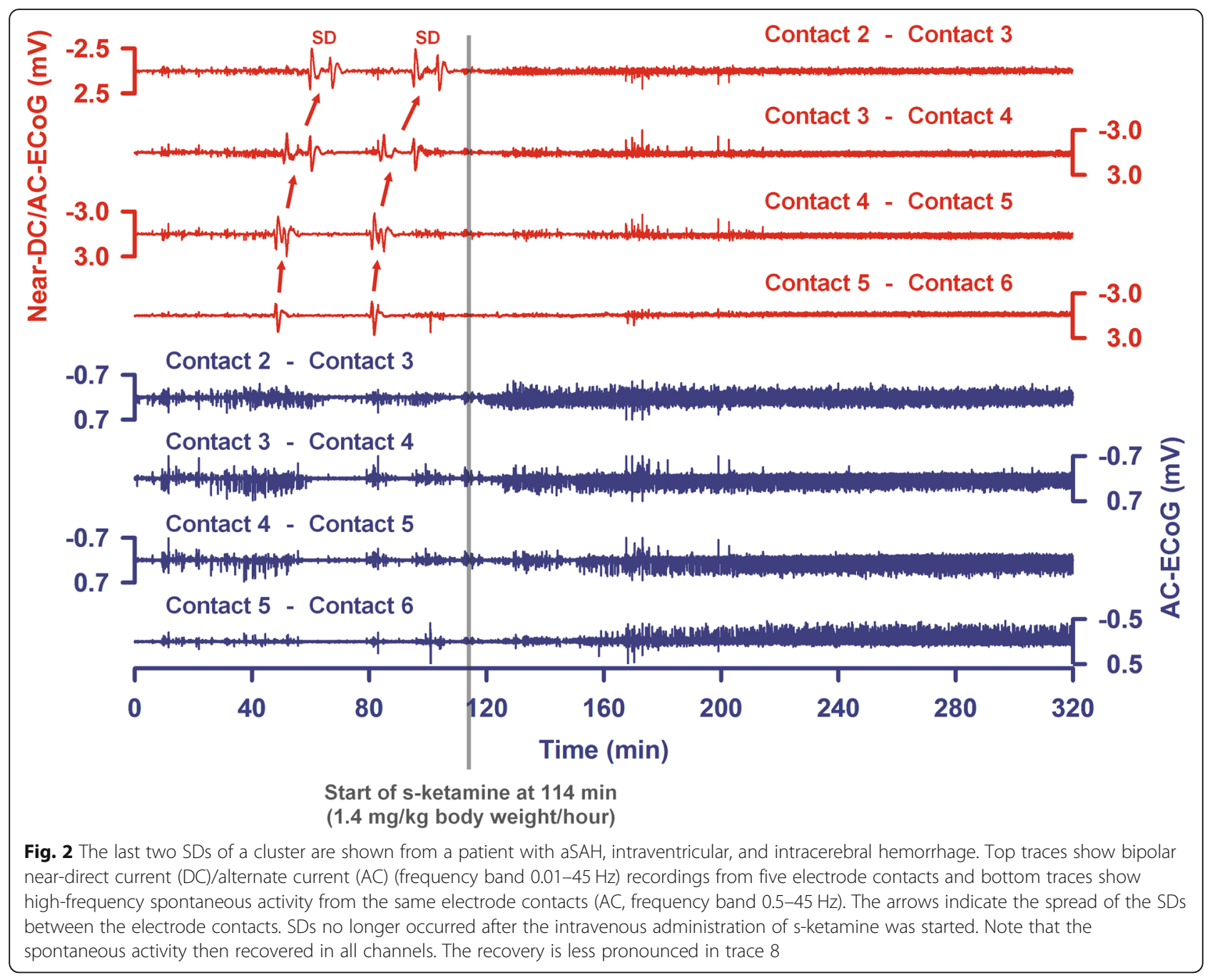

barbiturates were given, this represented less than $1 \%$ of the monitoring time.

For the purpose of the study, patients were divided according to whether or not s-ketamine (Ketanest $\mathrm{S}^{\ominus}$ ) was administered at any time during the ECoG monitoring. Doses of sedatives, ICP, and MAP were recorded hourly. MAP was recorded at the heart level. Glasgow Coma Score, blood gases, glucose, and electrolytes were documented every $6 \mathrm{~h}$. A thorough neurological examination was performed at least daily. Markers for infection (leucocytes and C-reactive protein (CRP)) were documented daily. Patients received a prophylaxis with oral nimodipine to prevent delayed cerebral ischemia (DCI). Patients with DCI were treated with hyperdynamic therapy as described previously [5]. Clinical outcome was assessed at 6 months according to the extended Glasgow Outcome Scale (eGOS, 1-8) by a neurologist, a neurosurgeon, or a trained study nurse. The large majority of survivors were seen and interviewed in person.
Data was mainly collected and coded by ES and AOR. AOR performed the ECoG analysis blinded to the clinical, pharmacological, and neuroimaging data. As a strategy to avoid errors and bias, the correctness of data coding was proofed by AHA and MGH. An analysis to detect extreme data and unusual data was done by ES. VK performed the analysis of the neuroimaging data blinded to the clinical, pharmacological, and ECoG data. The tables with the raw data were given to the statisticians to perform independently the predefined statistical analysis.

\section{Statistical analysis}

We provide the regression coefficient or the odds ratio for the group variable with $95 \%$ confidence intervals $(\mathrm{CI})$ and $p$ values. Note that the coefficient estimated in a negative binomial model describes the difference in the logarithm of the expected counts while in a linear model the coefficient can be interpreted as the mean difference between the groups. A $p$ value less than 5\% was 


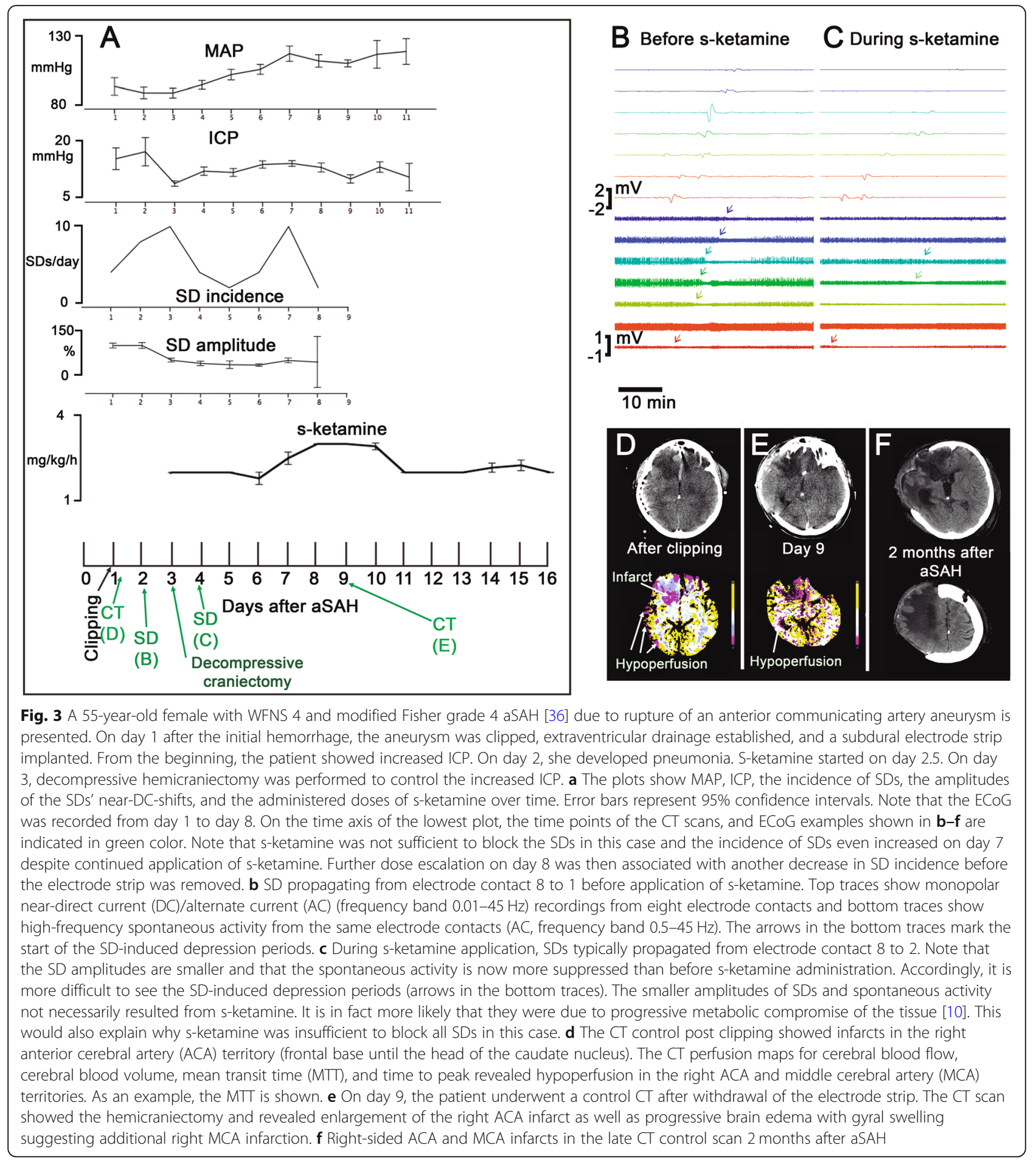

considered as statistically significant. However, all analyses are of explorative nature and have no confirmatory value. Therefore, no adjustment for multiple tests was applied. The analyses were carried out using the software $\mathrm{R}$ version 3.3.1 (https://www.r-project.org/) in combination with the packages nlme (https://cran.r-project.org/web/packages/nlme/index.html), lme4 (https:// www.jstatsoft.org/article/view/v067i01/0), MASS [38], xtable (https://cran.r-project.org/web/packages/xtable/ index.html), and Matrix (https://cran.r-project.org/web/ packages/Matrix/index.html).

In a first step, descriptive statistics were separately calculated for patients who received s-ketamine and patients who did not for all outcome variables of interest. 
For continuous variables, the mean values and standard deviations are provided. For categorical variables, absolute and relative frequencies were analyzed. In a next step, differences in the incidence of SDs and SD characteristics between the two patient groups were examined. Negative binomial models as well as (mixed) Poisson, logistic, or linear models were used as appropriate. When using mixed models, we took account of the clustered structure in the data (several observations per patients were measured) and the resulting correlation structure. The group variable (as a fixed effect) and a random intercept were included in the models as appropriate. In an additional analysis, we did not include the group variable but the indicator, if s-ketamine was given or not (one observation per hour).

\section{Results}

Table 1 gives a demographic summary of the 66 aSAH patients. SDs were detected in 51/66 patients (83\%). Thirtythree patients received s-ketamine during the monitoring period and 33 did not. Monitoring data of up to 19 days after aSAH was included in the analysis. S-ketamine administration started $4.2 \pm 3.5$ days (range $0-16$ ) after aSAH (cf. general protocol of sedation in "Materials and methods"). The mean dose was $2.8 \pm 1.4 \mathrm{mg} / \mathrm{kg} \mathrm{BW} / \mathrm{h}$. S-ketamine was given during a mean of $8.3 \pm 4.6$ days (range $1-15$ ).

The anesthesiologic standard procedures, as described in "Materials and methods," led to a strong selection bias such that patients who received s-ketamine had more severe aSAH (Table 1). Accordingly, (i) $79 \%$ of patients receiving s-ketamine but only $61 \%$ of patients not receiving s-ketamine showed WFNS 4 or 5 values at admission and (ii) $85 \%$ of patients receiving s-ketamine displayed a modified Fisher scale 4 hemorrhage at admission in contrast to only $64 \%$ of patients not receiving s-ketamine. Accordingly, the outcome of patients receiving s-ketamine was significantly worse (s-ketamine: eGOS 1-5: $n=30$, eGOS 6-8: $n=3$; no s-ketamine: eGOS 1-5: $n=21$, eGOS 6-8: $n=11$, Fisher exact test, $p=0.017$ ).

\section{S-ketamine effect on SDs on the patient level}

The 66 patients were first divided in two groups according to whether they received s-ketamine at any time of the monitoring or not. Patients who did not receive sketamine had 622 SDs overall, and the average number of SDs detected per patient was $18.9 \pm 29$.2. Patients who received s-ketamine had a total of 422 SDs, with an average of $12.8 \pm 17.6$ SDs per patient. The SD frequency was $0.08 \pm 0.32 \mathrm{SDs} / \mathrm{h}$ in patients who never received sketamine and $0.06 \pm 0.25 \mathrm{SDs} / \mathrm{h}$ in patients who did receive s-ketamine. Variables comparing both groups are presented in Fig. 4.

To determine whether there was a difference in SD incidence between the two groups, we first fitted a negative binomial model using the SD count per patient as outcome variable and the group (s-ketamine given vs. not given) as covariable. No significant difference in SD counts was found (coefficient $-0.39(-1.10 ; 0.33), p=0.288$ ), most likely because 368 SDs had already occurred in the s-ketamine group before the s-ketamine administration was initiated. Because most of the hourly counts were 0 , we additionally performed a logistic model. The sum per person was calculated and then dichotomized ( $>0$ vs. $=0$ ). Again, no difference was found between the groups (OR $0.59(0.18 ; 1.91), p=0.381)$. The expansion of SDs (percentage of channels invaded by SD in proportion to the channels available) was calculated for both groups, and no significant difference was found (coefficient $4.15(-7.41$; 15.72), $p=0.482$ ). The amplitude of the near-DC-shift was also compared using a linear mixed model, but similarly showed no difference (coefficient -7.68 (-26.10; 10.73), $p=0.414)$ on the patient level.

\section{S-ketamine effect on the incidence of SDs in hourly pooled data}

In Fig. 2, an example of a patient is given in whom clustered SDs were blocked by s-ketamine followed by a recovery of the spontaneous activity. In Fig. 3, we provide an example of a patient with DCI after aSAH in which the ECoG is also shown before and during s-ketamine application (Fig. 3b, c). However, not all SDs were blocked under s-ketamine in this case, although their characteristics changed.

We next grouped hourly data on the basis of whether or not s-ketamine was given in that hour. All 66 patients were included in this analysis, and the main patient findings are summarized in Fig. 5. The effect of s-ketamine on SD incidence was initially analyzed using a Poisson model with a random intercept for patient. We included the MAP in the model as a controlled variable because of the higher MAP during s-ketamine treatment (Fig. 6) and because it was previously found in patients with TBI that a higher MAP is associated with lower incidence of SDs [39]. We observed a significant decrease of the incidence of SDs when s-ketamine was given (coefficient $1.83(-2.17 ;-1.50), p<0.001)$. Because there were many observations with $\mathrm{SDs}=0$, a logistic regression model for the binary outcome SDs $=0$ vs. SDs $>0$ was estimated. The logistic regression model with random intercepts for patient showed a significant decrease in the incidence of SDs (OR 0.13 (0.08; 0.19), $p<0.001$ ). Linear mixed models were used to examine (i) the percentage of channels involved in SD in proportion to the channels available (expansion in \%) and (ii) the near-DC-shift amplitude. No significant change of expansion was found when s-ketamine was given (SD expansion: coefficient $6.24(-0.01 ; 12.50), p=0.05)$. In contrast, the amplitude of the near-DC-shift significantly decreased (coefficient $-29.20(-46.06 ;-12.35), p<0.001)$. 
Table 1 Summary of the clinical characteristics of the 66 aSAH patients

\begin{tabular}{|c|c|c|c|c|}
\hline & & No s-ketamine & s-ketamine & $p$ value \\
\hline \multicolumn{2}{|l|}{ Number of patients } & 33 & 33 & \\
\hline \multicolumn{2}{|l|}{ Male } & 9 & 15 & 0.125 \\
\hline \multicolumn{2}{|l|}{ Age } & $55.8 \pm 11.7$ & $51.1 \pm 8.0$ & 0.064 \\
\hline \multicolumn{2}{|l|}{ MAP (mmHg) } & $95.8 \pm 16.3$ & $100.7 \pm 8.1$ & 0.125 \\
\hline \multicolumn{2}{|l|}{ ICP (mmHg) } & $13.1 \pm 15.0$ & $11.2 \pm 4.1$ & 0.500 \\
\hline \multicolumn{2}{|l|}{ CPP (mmHg) } & $83.0 \pm 28.2$ & $89.6 \pm 8.9$ & 0.219 \\
\hline \multicolumn{2}{|l|}{ Pneumonia } & 16 & 20 & 0.323 \\
\hline \multicolumn{2}{|l|}{ Urinary tract infection } & 6 & 4 & 0.492 \\
\hline \multicolumn{2}{|l|}{ Monitoring days } & $14.8 \pm 4.9$ & $17.0 \pm 2.3$ & 0.024 \\
\hline \multicolumn{2}{|l|}{ AcoA } & 9 & 13 & 0.649 \\
\hline \multicolumn{2}{|l|}{ ACoP } & 2 & 1 & \\
\hline \multicolumn{2}{|l|}{$\mathrm{BCA}$} & 0 & 1 & \\
\hline \multicolumn{2}{|l|}{ ICA } & 3 & 3 & \\
\hline \multicolumn{2}{|l|}{ MCA } & 18 & 15 & \\
\hline \multicolumn{2}{|l|}{ PericA } & 1 & 0 & \\
\hline \multicolumn{2}{|l|}{ Aneurysm diameter } & $7.5 \pm 5.1$ & $7.3 \pm 4.4$ & 0.864 \\
\hline \multirow[t]{5}{*}{ WFNS } & 1 & 3 & 2 & 0.405 \\
\hline & 2 & 7 & 2 & \\
\hline & 3 & 3 & 3 & \\
\hline & 4 & 7 & 11 & \\
\hline & 5 & 13 & 15 & \\
\hline \multirow[t]{5}{*}{ Modified Fisher Scale } & 0 & 0 & 0 & 0.198 \\
\hline & 1 & 1 & 0 & \\
\hline & 2 & 1 & 0 & \\
\hline & 3 & 10 & 5 & \\
\hline & 4 & 21 & 28 & \\
\hline \multicolumn{2}{|l|}{$\mathrm{ICH}$} & 10 & 12 & 0.763 \\
\hline \multicolumn{2}{|l|}{ No ICH } & 23 & 21 & \\
\hline \multirow[t]{3}{*}{ Infarction } & Areal & 20 & 21 & 0.683 \\
\hline & Lacunar & 4 & 3 & \\
\hline & No & 9 & 9 & \\
\hline \multirow[t]{8}{*}{ eGOS } & 1 & 7 & 8 & 0.154 \\
\hline & 2 & 0 & 2 & \\
\hline & 3 & 7 & 6 & \\
\hline & 4 & 5 & 8 & \\
\hline & 5 & 2 & 6 & \\
\hline & 6 & 3 & 1 & \\
\hline & 7 & 4 & 1 & \\
\hline & 8 & 4 & 1 & \\
\hline
\end{tabular}

Neuroimaging was performed following standard care when clinical deterioration was noted. No strict imaging protocol was established for the purpose of the study. Therefore, caution is warranted in the interpretation of the imaging results. CT and/or magnetic resonance imaging (MRI) scans were analyzed to identify focal lesions (infarct or hemorrhage). VK analyzed the neuroimages blinded to the clinical courses and ECoG analyses. An infarct with a diameter $\leq$ $15 \mathrm{~mm}$ was denoted as "lacunar." An infarct $>15 \mathrm{~mm}$ was denoted as "areal." Hyperintensities in diffusion-weighted imaging (DWI) or hypodensities on CT resulting from ventricular catheters or intraparenchymal hematoma were documented as such. Intracerebral hemorrhages (ICH) appeared hypodense on later CT scans. These hypodensities as well as peri-hematomal hypodensities were denoted as "ICH" and not rated as ischemic lesions. All ICHs occurred during the initial hemorrhage. By contrast, ischemic infarcts could occur early or in a delayed fashion. The table reports whether patients developed an ischemic infarct at any time during the clinical course after the hemorrhage. Welch's $t$-tests or chi-squared tests were applied as appropriate. $A C O A$ anterior communicating artery, $A C O P$ posterior communicating artery, BCA basilar cerebral artery, ICA internal carotid artery, MCA middle cerebral artery, PericA pericallosal artery, WNFS World Federation of Neurosurgical Societies Sheart scale, eGOS extended Glasgow Outcome Scale 


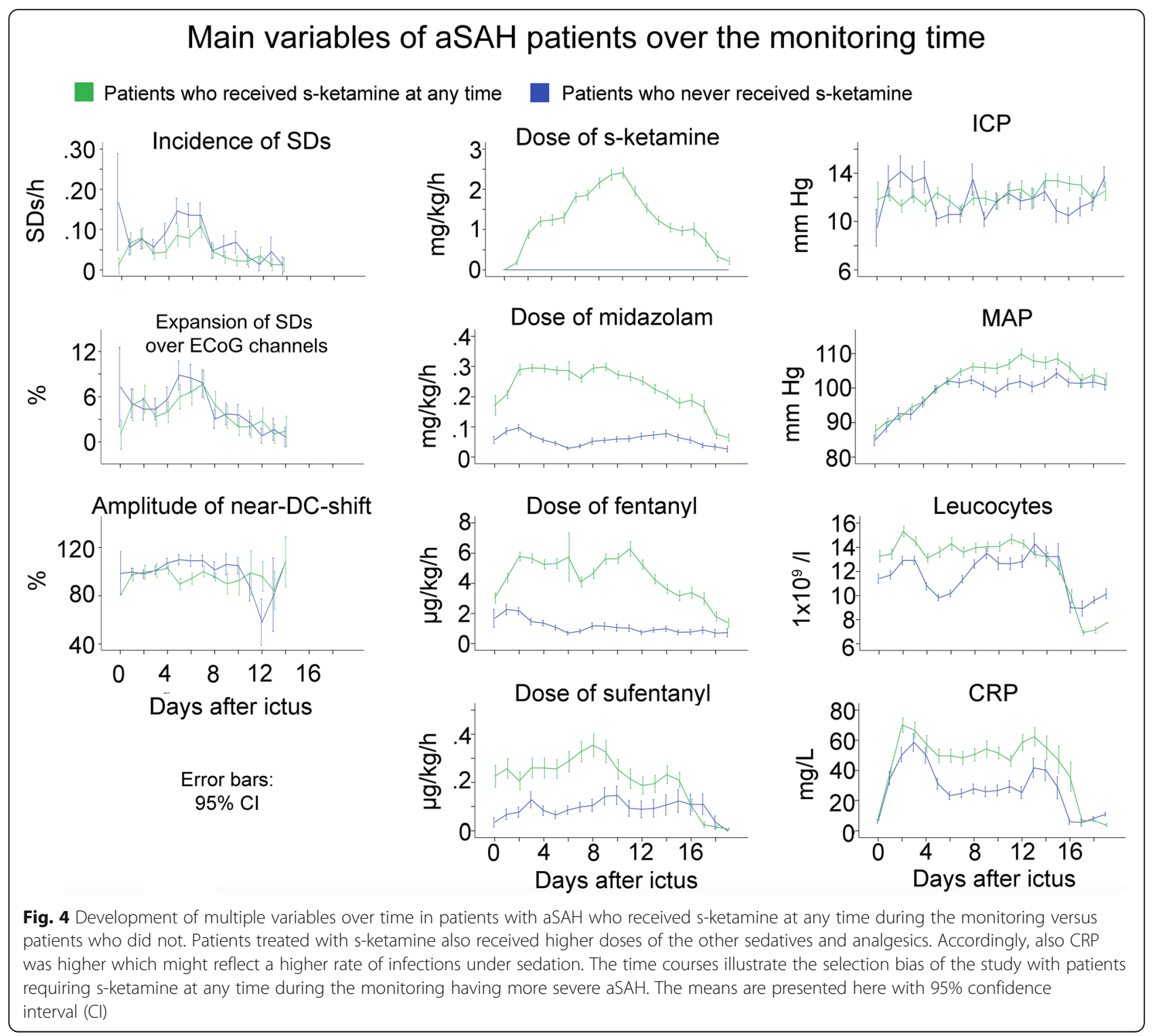

Thereafter, the hourly pooled data was further divided into low-dose (0.1-2.0 mg/kg BW/h) and high-dose (2.1$7.0 \mathrm{mg} / \mathrm{kg} / \mathrm{h}$ ) segments. The low-dose range is the therapeutic range supported by safety studies according to the manufacturer (Pfizer, New York, USA) whereas the highdose range is administered by intensivists in individual cases. The incidence of SDs was compared between lowand high-dose ranges using a Poisson model with a random intercept for patient using MAP as a controlled variable. High-dose s-ketamine was associated with further significant decrease in the incidence of SDs (coefficient $-1.10(-1.71 ;-0.49), p<0.001)$. Again, there were many observations with $\mathrm{SDs}=0$. Therefore, a logistic regression model for the binary outcome SDs $=0$ vs. SDs $>0$ was estimated. The logistic regression model with random intercepts for patients revealed a significant difference between the low- and high-dose ranges (OR 0.33 (0.17; $0.63), p<0.001)$. However, no significant difference was found in either SD expansion (coefficient $-3.23(-10.64$; 4.19), $p=0.393$ ) or the near-DC-shift amplitude (coefficient $-2.64(-18.11$; 23.38), $p=0.803)$ between the lowand high-dose ranges.

\section{Changes before and after s-ketamine application}

We also examined differences between the first day when s-ketamine was given and the preceding day. Only the 33 patients who received s-ketamine were considered (Fig. 6). There was a difference in all examined variables: incidence of SDs (coefficient $-1.38(-0.75 ;-2.00), p<$ $0.001)$, ICP (coefficient 1.30 (0.72; 1.88), $p<0.001$ ), MAP (coefficient 6.73 (5.80; 7.66), $p<0.001$ ), fentanyl (coefficient 1.47 (1.23; 1.72), $p<0.001$ ), midazolam (coefficient 

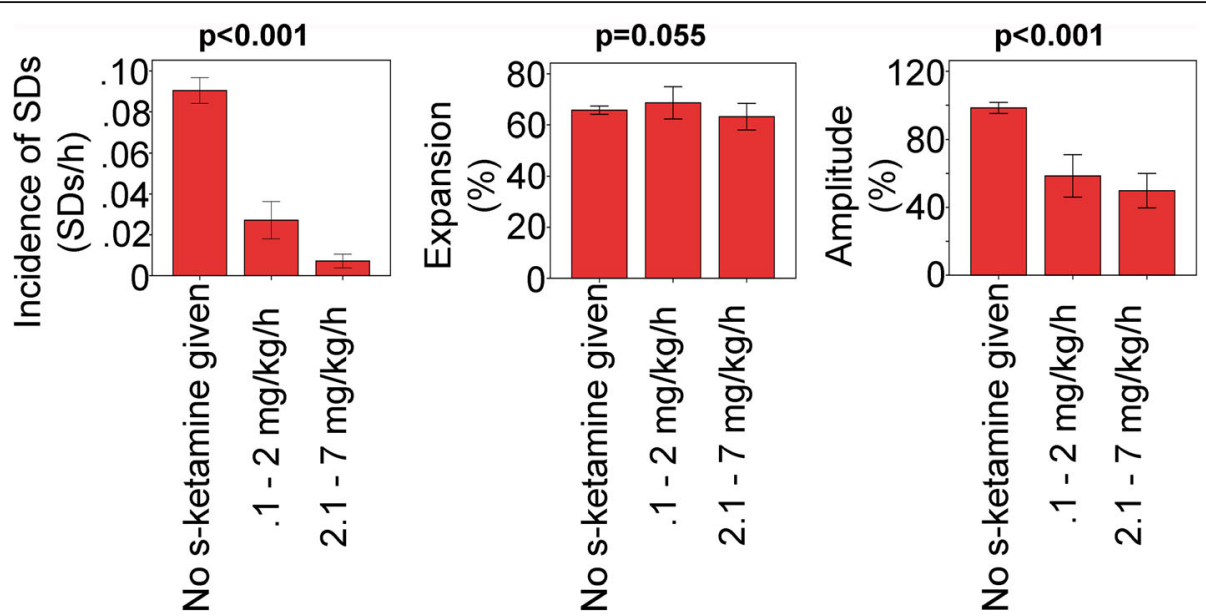

Error bars: $95 \%$ C.I.

Fig. 5 Incidence and characteristics of SDs in patients with aSAH dependent on s-ketamine. Patient data was hourly pooled according to whether s-ketamine was not given, given at a low dose or at a high dose. Data from the same patient could be in all three bars. For the statistical analysis, different models were used as described in "Results." $p$ values $<0.05$ mean that there was a difference between groups with $s-$ ketamine versus control without s-ketamine

0.07 (0.06; 0.08), $p<0.001$ ), propofol (coefficient -0.27 $(-0.18 ;-0.37), p<0.001)$, and sufentanyl (coefficient $0.06(-0.04 ;-0.09), p<0.001)$. Notably, it can be seen in Fig. 6 that the incidence of SDs gradually increased again after several days of s-ketamine, but clearly remained below the level without s-ketamine.

In addition, we determined the number of clustered SDs per recording day before and after s-ketamine administration, as described in "Materials and methods" and following the recent COSBID recommendations [37]. Whereas $1.3 \pm$ 2.7 clustered SDs per recording day were observed before s-ketamine administration, only $0.1 \pm 0.5$ were observed thereafter (Wilcoxon signed rank test, $p<0.001$ ). Finally, it should be mentioned that s-ketamine has a double effect on spontaneous brain activity. When administered during a cluster of SDs and the SDs are blocked, as in the example shown in Fig. 2, spontaneous brain activity can recover and the power of the activity re-increases. On the other hand, sketamine is assumed to have a direct suppressive effect on spontaneous brain activity, which means that the power of brain activity should decrease if no cluster takes place immediately before the administration of s-ketamine. This double effect could explain why we did not observe a significant change of the mean power of spontaneous brain activity between the day before s-ketamine administration and the first day during s-ketamine administration (Wilcoxon signed rank test, $p=0.096$ ).

\section{Discussion}

The foundations of the excitotoxicity concept in acute brain injury were first established by Anthonie van Harreveld in the 1950s. In a landmark paper, he proposed that glutamate is an important excitatory neurotransmitter, causing contraction when applied to crustacean muscle [40]. Yet, he also found that glutamate triggers the pathologic reaction of SD when applied to the cerebral cortex, and conversely, provided evidence that SD causes the release of glutamate into the interstitial space when it invades a normal, undisturbed cortex. The toxic aspect of this process was evidenced by an increased tissue impedance during SD, which suggested a shift of electrolytes from the extra- to the intracellular compartment, as reviewed recently [7]. Electron microscopy then confirmed the swelling of neuronal somas, dendrites, and mitochondria as a consequence of the breakdown of electrochemical gradients. Importantly, these changesthe release of glutamate and the cytotoxic edema-occurred similarly as a result of both SD and severe cerebral ischemia, suggesting that the former mediates damage from the latter. Unfortunately, these insights were lost when Olney (1969) [41] and then Choi (1980s) [42] were credited with the discovery of glutamate excitoxicity, which was then characterized and studied without consideration of the SD mechanism. Thus, neuroprotectants against stroke or TBI were not developed or assessed for dosing efficacy against SDs occurring in metabolically compromised regions [43]. Instead, they aimed at doses with negligible psychotropic effects, although the literature suggested that these would not be sufficient to block SDs where they are harmful. Accordingly, there was no evidence of significant benefit or harm from these drugs in the ensuing clinical trials [44].

Maintaining wakefulness and avoiding delirium are, without doubt, important goals in alert patients with 


\section{aSAH patients who received s-ketamine}
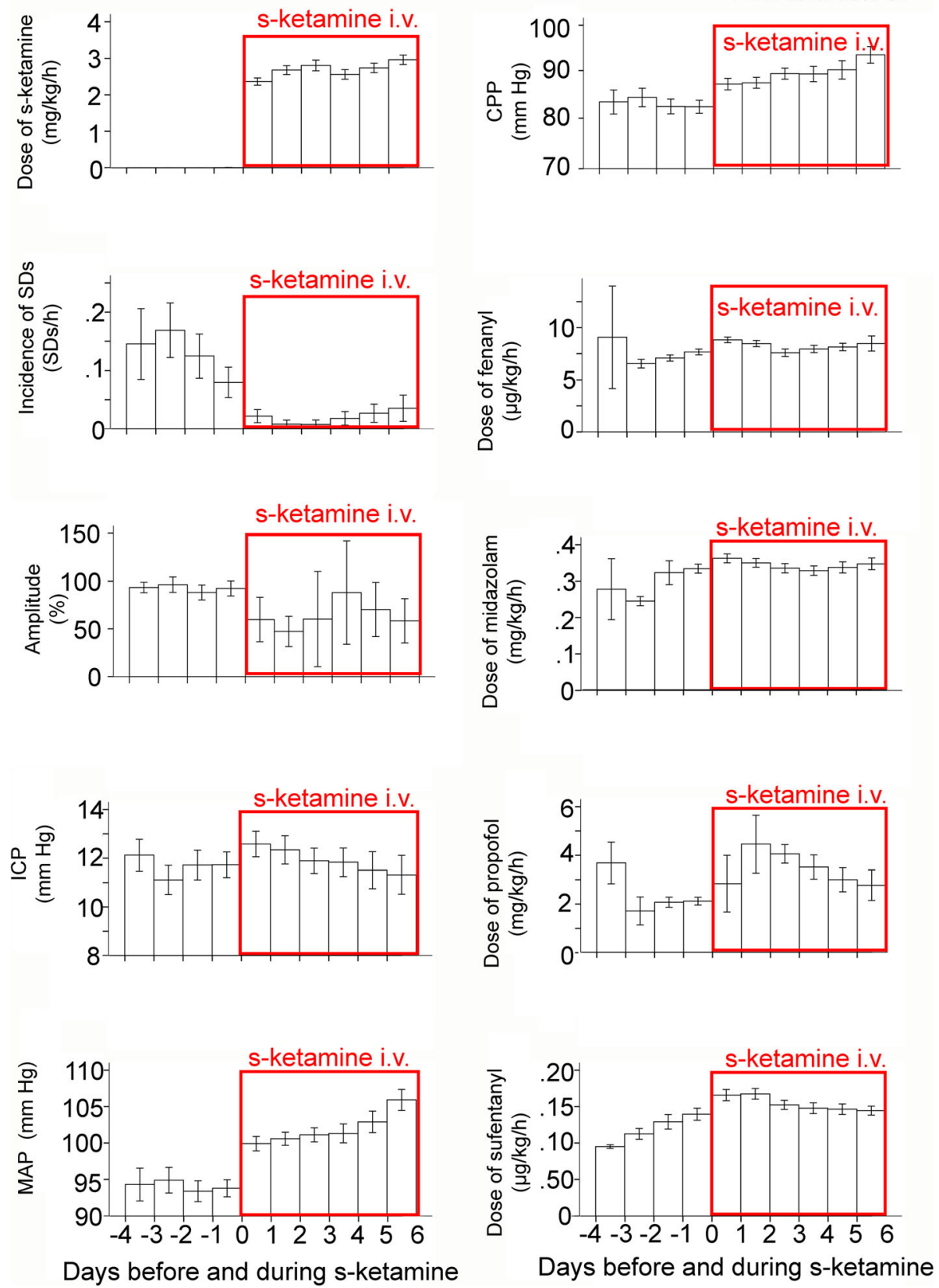

Fig. 6 Data classified as a function of the time point when s-ketamine was applied. The means are presented here with 95\% confidence interval (Cl). When s-ketamine was discontinued, subsequently recorded data was not used for this analysis. Note that (i) the mean dose of s-ketamine was above $2 \mathrm{mg} / \mathrm{kg}$ BW/h and (ii) all variables analyzed showed a difference before and after s-ketamine. The incidence of SDs showed a clear and lasting reduction in response to s-ketamine

stroke or TBI. For example, sedation often necessitates intubation and ventilation. Each day of mechanical ventilation increases the risk of pneumonia [45], which is in turn associated with worse outcome [46]. Thus, when aiming at the administration of neuroprotectants to alert patients, drug developers rightly wanted to avoid psychotropic side effects. These conditions may have been self-defeating, however, as neuroprotective benefit of NMDAR antagonists was likely not possible at such doses. On the other hand, these considerations suggest that NMDAR antagonists may still be promising candidate drugs to protect neurons when patients with acute cerebral injuries require sedation. In this respect, it is interesting that one of the NMDAR antagonists has found 
its way into routine neurocritical care practice to sedate patients with acute cerebral injuries, including aSAH. This development has occurred in a more or less unsystematic fashion, driven by clinical experience rather than higher-level scientific evidence, and concerns the open channel NMDAR blocker, ketamine.

Ketamine is a dissociative anesthetic causing doserelated analgesia and unconsciousness. Observable analgesia is achieved at doses between 0.1 and $0.5 \mathrm{mg} / \mathrm{kg}$, while anesthesia requires doses over $1 \mathrm{mg} / \mathrm{kg}$ [47]. The active enantiomer $\mathrm{S}(+)$ ketamine (s-ketamine) is two times stronger than the racemic form and four times stronger than the $\mathrm{R}(-)$ enantiomer [48]. In contrast to the USA, where s-ketamine is not licensed and the racemic mixture is used, s-ketamine is licensed and frequently applied in Germany. The upper therapeutically recommended dose of s-ketamine for sedation is $2 \mathrm{mg} / \mathrm{kg} \mathrm{BW} / \mathrm{h}$, but, if deemed necessary, neurointensivists are using doses of up to $7 \mathrm{mg} / \mathrm{kg} \mathrm{BW} / \mathrm{h}$. Combination with the $\mathrm{GABA}_{\mathrm{A}}$ agonist midazolam is standard to avoid ICP increases that are presumably related to ketamine's psychotomimetic effects.

The present study is the largest one to date on the effect of s-ketamine on SDs in aSAH patients. We found that s-ketamine administration was associated with a reduced SD incidence and a reduced amplitude of the near-DC-shift. Importantly, SDs were most potently inhibited by doses of s-ketamine that are above clinically recommended doses, but are nonetheless given by neurointensivists in individual cases. An important limitation is the retrospective study design. This led to the selection bias that the sicker patients were treated with s-ketamine. Thus, patients receiving s-ketamine more frequently showed WFNS 4 or 5 values at admission and had more severe aSAH on the modified Fisher scale [36], which is the most likely reason why s-ketaminetreated patients had a worse outcome. However, it cannot be completely excluded that the s-ketamine group experienced more severe secondary complications due to, for example, stronger sedation, as explained above. This can only be clarified in a prospective trial. Such a trial should be preceded by a feasibility study, as we do not yet know enough about the practicability of neuromonitoring-guided treatment protocols in general and about the aggressiveness, timing, and duration of the treatment of SDs in particular.

Non-competitive NMDAR antagonists such as ketamine bind at the phencyclidine receptor site within the NMDAR-controlled non-selective cation channel. A problem, previously observed in rats and specific to this type of NMDAR antagonists, is the use-dependent development of tolerance, which typically appeared after several SD waves were elicited under ketamine [35]. Use-dependency refers to the fact that the tolerance only developed in presence of glutamate, the receptor agonist, which is repeatedly released at high concentrations during repetitive SDs $[49,50]$. It was proposed that this results from conformational changes at the binding site [49]. In our patients, we did not find clear evidence for the development of tolerance against s-ketamine. The reservation, however, is that the group of Bures had to induce SDs in rats at regular intervals of $\sim 15 \mathrm{~min}$ in order to induce the usedependent tolerance. Therefore, we cannot rule out a tolerance in patients when SDs occur in a high rate cluster [4]. Nonetheless, the present results are important because they dispel concerns that s-ketamine would rapidly and in a clearly visible manner lose efficacy against SDs when applied to patients over a prolonged period. Another concern is that ketamine could increase ICP. Although significant, we found only a small and clinically irrelevant increase. MAP also increased. In the DCI phase, however, this is rather a positive side effect.

Our results do not address the other important concern that NMDAR antagonists are generally insufficient to block terminal SD in severely ischemic tissue [23-26]. Rodent brain slice experiments suggested that additional ion channels are recruited into the SD-generating mechanism with increasing metabolic failure [26, 51, 52]. Thus, only a bathing medium containing high concentrations of, e.g., DNQX/NBQX to block all AMPA/kainate receptors, the combination of MK-801 and APV to potently block NMDARs, and bicuculline methiodide to block $\mathrm{GABA}_{\mathrm{A}}$ receptors succeeded in preventing $\mathrm{SD}$ in severely ischemic/hypoxic tissue. The required concentrations were so high that it is difficult to see how they could be achieved in vivo without causing significant toxic side effects [52]. Yet, as explained above, SD can trigger spreading ischemia even in tissue with relatively preserved metabolism [19]. This SD-mediated vasoconstriction can then induce severe energy deprivation in the tissue. Thus, by blocking the spread of SDs into such regions of impaired neurovascular coupling, NMDAR antagonists may still offer substantial neuroprotective benefit. Recent monitoring of ECoG, regional cerebral blood flow, and tissue partial pressure of oxygen in aSAH patients supported this notion [10]. For example, in one case, a short-lasting SD triggered a brief hypoperfusion at one optoelectrode pair. From there, the SD spread to the adjacent optoelectrode pair, where it caused a spreading ischemia of more than $50 \mathrm{~min}$ duration, leading to a so-called negative ultraslow potential (NUP). The NUP specifically refers to a negative potential component during progressive recruitment of neurons into cell death in the wake of SDs [7]. Serial neuroimages proved that an infarct developed at the recording site.

Another concern complicating the neuroprotective use of NMDAR antagonists is a potentially beneficial effect of SDs in healthy tissue, in contrast to metabolically impaired 
tissue. In otherwise normal tissue, SDs upregulate growth factors, stress response proteins, and inflammatory mediators, may have preconditioning actions, and could enhance plasticity and regeneration [12, 27, 53]. This remains a theoretical consideration, as there is no conclusive evidence that SDs are beneficial in regions remote from injured cortex, and the net effect of inhibiting SDs with NMDAR antagonists was protective in most experimental focal ischemia studies [54-58]. Nevertheless, a recent experimental study in brain slices should not go unmentioned in which ketamine significantly reduced the neuronal $\mathrm{Ca}^{2+}$ surge during SD in parallel with SD's duration and accelerated the recovery of postsynaptic potentials after SD in tissue with mildly impaired metabolism, but SD initiation and propagation remained preserved [59]. These results were interpreted to suggest that a lower dose might be more beneficial than a higher dose of ketamine.

In the present study, the occurrence of electrographic seizures in the ECoG recordings was not systematically analyzed, which is a limitation. Another limitation is that we did not perform continuous scalp electroencephalography to detect electrographic seizures. However, in a previous pilot study of 25 patients with aSAH, we found electrographic seizures in $12 \%$ of the ECoG recordings [60]. Ketamine inhibits epileptic activity in animal models [61] and has been successfully used as a third- or fourth-line treatment of refractory status epilepticus in patients [62]. On this basis, it is expected that the administration of ketamine should not only inhibit SDs but also electrographic seizures. This could be another argument for the use of ketamine and should be systematically studied in a prospective trial. In our previous study, we also observed that patients who developed late epilepsy within 3 years after the hemorrhage showed a higher peak number of SDs during the early clinical course [60]. In the present study, we did not investigate whether inhibition of SDs by s-ketamine reduced the frequency of late epilepsy, but we recommend that this interesting research and clinical question should be included in a future prospective trial.

Another limitation is the use of a single electrode strip to detect SDs. Although SDs propagate widely from metabolically stressed zones, there is evidence from both clinical studies, including the present one, and animal studies that a fraction of SDs is rather localized [33, 63-66]. Therefore, if neuromonitoring is used to guide the administration of ketamine, clusters of SDs may be overlooked if the electrode strip is too far away from the metabolically disturbed region. No significant complications have been observed using a single electrode strip to detect SDs [45]. The strip does not require an operation for the removal and can be easily withdrawn at the bedside. Thus, the current practice is a trade-off between patient safety and benefit. However, by using an additional strip, the significance of the recordings could presumably be increased without significantly increasing the risk for the patient. Alternatively, it was proposed to place depth electrodes subdurally, which could facilitate implantation through a burr hole and would allow more electrodes to be implanted that could still be removed at the bedside [9]. The advantage of placing depth electrodes in the subdural space and not in the parenchyma would be that injury and inflammation of the parenchyma would be avoided [37]. At the same time, the probability of detecting SDs would increase as they are recorded from more than one cortical location [67].

\section{Conclusions}

ECoG neuromonitoring offers the potential advantage of performing early treatment stratification according to SDs detected in real time, and then to document the response to a neuroprotective intervention with subsequent dose adjustments in an iterative fashion [27]. Furthermore, SDs are a promising diagnostic summary measure because they propagate widely from metabolically stressed zones, thereby affording even remote detection of newly developing injury. A pressing clinical question in this context is whether sedation-requiring individuals undergoing clusters of SDs in the wake of acute cerebral injuries should receive the combination of midazolam and ketamine rather than midazolam and propofol-the usual first-line combination treatment in neurocritical care-in order to prevent SDs that carry the risk of triggering spreading ischemias. The present results provide the foundation to address this question with a feasibility study for a neuromonitoring-guided, randomized, blinded, multicenter, proof-of-concept trial. The fundamental question is whether ketamine should be started earlier in the event of SDs, in contrast to the delay in ketamine use observed here in current practice, in order to offer a greater chance for neuroprotection. In such a trial, ketamine could be tested at both the currently recommended dose for sedation and a higher one that is still often administered in current clinical practice.

\section{Abbreviations \\ ACA: Anterior cerebral artery; aSAH: Aneurysmal subarachnoid hemorrhage; BW: Body weight; Cl: Confidence intervals; CPP: Cerebral perfusion pressure; CRP: C-reactive protein; CT: Computed tomography; DC: Direct current; DCl: Delayed cerebral ischemia; ECoG: Electrocorticography; eGOS: Extended Glasgow Outcome Scale; ICP: Intracranial pressure; MAP: Mean arterial blood pressure; MCA: Middle cerebral artery; MTT: Mean transit time; NMDAR: N- Methyl-D-aspartate receptor; NUP: Negative ultraslow potential; SD: Spreading depolarization; TBI: Traumatic brain injury; WFNS: World Federation of Neurosurgical Societies scale}

\section{Acknowledgments}

We acknowledge all nurses and clinicians who contributed to the study.

\section{Authors' contributions}

ES designed the project, collected patients, analyzed data, and wrote the manuscript together with JPD. AOR, RSP, RZ, MK, AHA, MGH, and CL 
analyzed the data and corrected the manuscript. SM, JW, and OWS collected patients and corrected the manuscript. LU and KK performed the statistical analysis and corrected the manuscript. VK analyzed patient data and corrected the manuscript. JAH gave intellectual input and corrected the manuscript. OWS and AWU designed the prospective observational study, provided scientific support, and corrected the manuscript. JPD designed the prospective observational study, collected the patients, provided scientific support, and wrote the manuscript together with ES. All authors read and approved the final manuscript

\section{Funding}

Dr. Edgar Santos Marcial was supported by the Physician Scientist Program from the University of Heidelberg. In addition, the work was supported by grants of the Bundesministerium für Bildung und Forschung (BMBF) Center for Stroke Research Berlin 01 EO 0801 and Deutsche Forschungsgemeinschaft (DFG) DFG DR 323/10-1 to Dr. Dreier, Era-Net Neuron EBio2 to Dr. Dreier, FP7 no 602150 CENTER-TBI to Drs. Dreier and Sakowitz, DFG DR 323/5-1 to Drs. Dreier, Woitzik and Sakowitz, DFG WO 1704/1-1 to Dr. Woitzik and the US Army CDMRP PH/TBI Research Program (Contract No. W81XWH-08-2-0016) to Dr. Hartings. The funding bodies did not have a role in the management or interpretation of the information.

\section{Availability of data and materials}

Electronic recording, processing, and storage of the data were approved by the data protection officer of the Charité - Universitätsmedizin Berlin. The raw datasets analyzed during the current study are not publicly available because the patient's informed consent only permits the data analysis and publication by the investigators.

\section{Ethics approval and consent to participate}

The protocol was approved by the local ethics committees of the CharitéUniversitätsmedizin Berlin and the University of Heidelberg. Either informed consent or surrogate informed consent was obtained for all patients. All procedures performed were in accordance with the 1964 Helsinki Declaration and its later amendments.

\section{Consent for publication}

Not applicable.

\section{Competing interests}

The authors declare that they have no competing interests.

\section{Author details}

${ }^{1}$ Neurosurgery Department, Heidelberg University HospitalRuprecht-Karls-Universität Heidelberg, Im Neuenheimer Feld 400, 69120 Heidelberg, Germany. ${ }^{2}$ Center for Stroke Research Berlin, CharitéUniversitätsmedizin Berlin, Freie Universität Berlin, Humboldt-Universität zu Berlin, and Berlin Institute of Health, Berlin, Germany. ${ }^{3}$ Department of Neurology, Charité-Universitätsmedizin Berlin, Freie Universität Berlin, Humboldt-Universität zu Berlin, and Berlin Institute of Health, Berlin, Germany. ${ }^{4}$ Department of Experimental Neurology, CharitéUniversitätsmedizin Berlin, Freie Universität Berlin, Humboldt-Universität zu Berlin, and Berlin Institute of Health, Berlin, Germany. ${ }^{5}$ Institute of Medical Biometry and Informatics, Ruprecht-Karls-University Heidelberg, Heidelberg, Germany. ${ }^{6}$ Evangelisches Krankenhaus Oldenburg, University of Oldenburg, Oldenburg, Germany. ${ }^{7}$ UC Gardner Neuroscience Institute, University of Cincinnati (UC) College of Medicine, Cincinnati, OH, USA. ${ }^{8}$ Department of Neurosurgery, University of Cincinnati (UC) College of Medicine, Cincinnati, $\mathrm{OH}$, USA. ${ }^{9}$ Neurosurgery Center Ludwigsburg-Heilbronn, RKH Klinikum Ludwigsburg, Ludwigsburg, Germany. ${ }^{10}$ Bernstein Center for Computational Neuroscience Berlin, Berlin, Germany. ${ }^{11}$ Einstein Center for Neurosciences Berlin, Berlin, Germany.

Received: 23 July 2019 Accepted: 16 December 2019

Published online: 30 December 2019

\section{References}

1. Vergouwen MD, Vermeulen M, van Gijn J, Rinkel GJ, Wijdicks EF, Muizelaar $J$, et al. Definition of delayed cerebral ischemia after aneurysmal subarachnoid hemorrhage as an outcome event in clinical trials and observational studies: proposal of a multidisciplinary research group. Stroke. 2010;41(10):2391-5.

2. Dreier JP, Sakowitz OW, Harder A, Zimmer C, Dirnagl U, Valdueza JM, et al. Focal laminar cortical MR signal abnormalities after subarachnoid hemorrhage. Ann Neurol. 2002;52(6):825-9.

3. Dreier JP, Lemale CL, Kola V, Friedman A, Schoknecht K. Spreading depolarization is not an epiphenomenon but the principal mechanism of the cytotoxic edema in various gray matter structures of the brain during stroke. Neuropharmacology. 2018;134(Pt B):189-207.

4. Dreier JP, Woitzik J, Fabricius M, Bhatia R, Major S, Drenckhahn C, et al. Delayed ischaemic neurological deficits after subarachnoid haemorrhage are associated with clusters of spreading depolarizations. Brain. 2006;129(Pt 12):3224-37.

5. Dreier JP, Major S, Manning A, Woitzik J, Drenckhahn C, Steinbrink J, et al. Cortical spreading ischaemia is a novel process involved in ischaemic damage in patients with aneurysmal subarachnoid haemorrhage. Brain. 2009;132(Pt 7):1866-81.

6. Sakowitz OW, Santos E, Nagel A, Krajewski KL, Hertle DN, Vajkoczy P, et al. Clusters of spreading depolarizations are associated with disturbed cerebral metabolism in patients with aneurysmal subarachnoid hemorrhage. Stroke. 2013;44(1):220-3.

7. Dreier JP, Major S, Foreman B, Winkler MKL, Kang EJ, Milakara D, et al. Terminal spreading depolarization and electrical silence in death of human cerebral cortex. Ann Neurol. 2018;83(2):295-310.

8. Carlson AP, Shuttleworth CW, Major S, Lemale CL, Dreier JP, Hartings JA Terminal spreading depolarizations causing electrocortical silencing prior to clinical brain death: case report. J Neurosurg. 2018;131(6):1683-994.

9. Dreier JP, Major S, Lemale CL, Kola V, Reiffurth C, Schoknecht K, et al. Correlates of spreading depolarization, spreading depression, and negative ultraslow potential in epidural versus subdural electrocorticography. Front Neurosci. 2019;13:373.

10. Luckl J, Lemale $\mathrm{CL}$, Kola V, Horst V, Khojasteh U, Oliveira-Ferreira Al, et al. The negative ultraslow potential, electrophysiological correlate of infarction in the human cortex. Brain. 2018;141(6):1734-52.

11. Oliveira-Ferreira Al, Milakara D, Alam M, Jorks D, Major S, Hartings JA, et al. Experimental and preliminary clinical evidence of an ischemic zone with prolonged negative DC shifts surrounded by a normally perfused tissue belt with persistent electrocorticographic depression. J Cereb Blood Flow Metab. 2010;30(8):1504-19.

12. Hartings JA, York J, Carroll CP, Hinzman JM, Mahoney E, Krueger B, et al. Subarachnoid blood acutely induces spreading depolarizations and early cortical infarction. Brain. 2017;140(10):2673-90.

13. Drenckhahn C, Winkler MK, Major S, Scheel M, Kang EJ, Pinczolits A, et al. Correlates of spreading depolarization in human scalp electroencephalography. Brain. 2012;135(Pt 3):853-68.

14. Major S, Huo S, Lemale CL, Siebert E, Milakara D. Woitzik J, et al. Geroscience: Direct electrophysiological evidence that spreading depolarization-induced spreading depression is the pathophysiological correlate of the migraine aura and a review of the spreading depolarization continuum of acute neuronal mass injury; 2019.

15. Dreier JP, Reiffurth C. The stroke-migraine depolarization continuum. Neuron. 2015;86(4):902-22.

16. Dreier JP, Korner K, Ebert N, Gorner A, Rubin I, Back T, et al. Nitric oxide scavenging by hemoglobin or nitric oxide synthase inhibition by $\mathrm{N}$-nitro-Larginine induces cortical spreading ischemia when $\mathrm{K}+$ is increased in the subarachnoid space. J Cereb Blood Flow Metab. 1998;18(9):978-90.

17. Shin HK, Dunn AK, Jones PB, Boas DA, Moskowitz MA, Ayata C. Vasoconstrictive neurovascular coupling during focal ischemic depolarizations. J Cereb Blood Flow Metab. 2006;26(8):1018-30.

18. Dreier JP, Petzold G, Tille K, Lindauer U, Arnold G, Heinemann U, et al. Ischaemia triggered by spreading neuronal activation is inhibited by vasodilators in rats. J Physiol. 2001;531(Pt 2):515-26.

19. Dreier JP, Ebert N, Priller J, Megow D, Lindauer U, Klee R, et al. Products of hemolysis in the subarachnoid space inducing spreading ischemia in the cortex and focal necrosis in rats: a model for delayed ischemic neurological deficits after subarachnoid hemorrhage? J Neurosurg. 2000;93(4):658-66.

20. Marrannes R, Willems R, De Prins E, Wauquier A. Evidence for a role of the $\mathrm{N}$-methyl-D-aspartate (NMDA) receptor in cortical spreading depression in the rat. Brain Res. 1988;457(2):226-40.

21. Nedergaard M, Hansen AJ. Spreading depression is not associated with neuronal injury in the normal brain. Brain Res. 1988;449(1-2):395-8. 
22. Petzold GC, Windmuller O, Haack S, Major S, Buchheim K, Megow D, et al. Increased extracellular $\mathrm{K}+$ concentration reduces the efficacy of N-methyl-Daspartate receptor antagonists to block spreading depression-like depolarizations and spreading ischemia. Stroke. 2005;36(6):1270-7.

23. Hernandez-Caceres J, Macias-Gonzalez R, Brozek G, Bures J. Systemic ketamine blocks cortical spreading depression but does not delay the onset of terminal anoxic depolarization in rats. Brain Res. 1987;437(2):360-4.

24. Lauritzen M, Hansen AJ. The effect of glutamate receptor blockade on anoxic depolarization and cortical spreading depression. J Cereb Blood Flow Metab. 1992;12(2):223-9.

25. Muller M, Somjen GG. Inhibition of major cationic inward currents prevents spreading depression-like hypoxic depolarization in rat hippocampal tissue slices. Brain Res. 1998;812(1-2):1-13.

26. Madry C, Haglerod C, Attwell D. The role of pannexin hemichannels in the anoxic depolarization of hippocampal pyramidal cells. Brain. 2010;133(Pt 12):3755-63.

27. Dreier JP. The role of spreading depression, spreading depolarization and spreading ischemia in neurological disease. Nat Med. 2011;17(4):439-47.

28. Sakowitz OW, Kiening KL, Krajewski KL, Sarrafzadeh AS, Fabricius M, Strong AJ, et al. Preliminary evidence that ketamine inhibits spreading depolarizations in acute human brain injury. Stroke. 2009;40(8):e519-22.

29. Hertle DN, Dreier JP, Woitzik J, Hartings JA, Bullock R, Okonkwo DO, et al. Effect of analgesics and sedatives on the occurrence of spreading depolarizations accompanying acute brain injury. Brain. 2012;135(Pt 8):2390-8.

30. Carlson AP, Abbas M, Alunday RL, Qeadan F, Shuttleworth CW. Spreading depolarization in acute brain injury inhibited by ketamine: a prospective, randomized, multiple crossover trial. J Neurosurg. 2018;130(5):1409-788.

31. Hartings JA, Ngwenya LB, Carroll CP, Foreman B. Letter to the Editor. Ketamine sedation for the suppression of spreading depolarizations. J Neurosurg. 2018;130(6):1789-2097.

32. Schiefecker AJ, Beer R, Pfausler B, Lackner P, Broessner G, Unterberger I, et al. Clusters of cortical spreading depolarizations in a patient with intracerebral hemorrhage: a multimodal neuromonitoring study. Neurocrit Care. 2015;22(2):293-8.

33. Sanchez-Porras R, Santos E, Scholl M, Stock C, Zheng Z, Schiebel P, et al. The effect of ketamine on optical and electrical characteristics of spreading depolarizations in gyrencephalic swine cortex. Neuropharmacology. 2014;84:52-61.

34. Sanchez-Porras R, Santos E, Scholl M, Kunzmann K, Stock C, Silos H, et al Ketamine modulation of the haemodynamic response to spreading depolarization in the gyrencephalic swine brain. J Cereb Blood Flow Metab. 2017;37(5):1720-34.

35. Amemori T, Bures J. Ketamine blockade of spreading depression: rapid development of tolerance. Brain Res. 1990;519(1-2):351-4.

36. Frontera JA, Claassen J, Schmidt JM, Wartenberg KE, Temes R, Connolly ES $\mathrm{Jr}$, et al. Prediction of symptomatic vasospasm after subarachnoid hemorrhage: the modified fisher scale. Neurosurgery. 2006;59(1):21-7. discussion -7

37. Dreier JP, Fabricius M, Ayata C, Sakowitz OW, William Shuttleworth C, Dohmen C, et al. Recording, analysis, and interpretation of spreading depolarizations in neurointensive care: review and recommendations of the COSBID research group. J Cereb Blood Flow Metab. 2017;37(5):1595-625.

38. Venables WN, Ripley BD. Modern applied statistics with S. 4th ed. New York: Springer; 2002

39. Hartings JA, Strong AJ, Fabricius M, Manning A, Bhatia R, Dreier JP, et al. Spreading depolarizations and late secondary insults after traumatic brain injury. J Neurotrauma. 2009;26(11):1857-66.

40. van Harreveld A. Compounds in brain extracts causing spreading depression of cerebral cortical activity and contraction of crustacean muscle. J Neurochem. 1959;3:300-15.

41. Olney JW. Brain lesions, obesity, and other disturbances in mice treated with monosodium glutamate. Science. 1969;164(3880):719-21.

42. Choi DW, Maulucci-Gedde M, Kriegstein AR. Glutamate neurotoxicity in cortical cell culture. J Neurosci. 1987:7(2):357-68

43. Klass A, Sanchez-Porras R, Santos E. Systematic review of the pharmacological agents that have been tested against spreading depolarizations. J Cereb Blood Flow Metab. 2018;38(7):1149-79.

44. Muir KW, Lees KR. Excitatory amino acid antagonists for acute stroke. Cochrane Database Syst Rev. 2003;3:CD001244

45. Drenckhahn C, Windler C, Major S, Kang EJ, Scheel M, Vajkoczy P, et al. Complications in aneurysmal subarachnoid hemorrhage patients with and without subdural electrode strip for electrocorticography. J Clin Neurophysiol. 2016;33(3):250-9.
46. Wartenberg KE, Schmidt JM, Claassen J, Temes RE, Frontera JA, Ostapkovich $\mathrm{N}$, et al. Impact of medical complications on outcome after subarachnoid hemorrhage. Crit Care Med. 2006;34(3):617-23. quiz 24

47. Tyler MW, Yourish HB, lonescu DF, Haggarty SJ. Classics in chemical neuroscience: ketamine. ACS Chem Neurosci. 2017;8(6):1122-34.

48. Mion G, Villevieille T. Ketamine pharmacology: an update (pharmacodynamics and molecular aspects, recent findings). CNS Neurosci Ther. 2013;19(6):370-80.

49. Rashidy-Pour A, Motaghed-Larijani Z, Bures J. Tolerance to ketamineinduced blockade of cortical spreading depression transfers to MK-801 but not to AP5 in rats. Brain Res. 1995:693(1-2):64-9.

50. Hinzman JM, DiNapoli VA, Mahoney EJ, Gerhardt GA, Hartings JA. Spreading depolarizations mediate excitotoxicity in the development of acute cortical lesions. Exp Neurol. 2015;267:243-53.

51. Rossi DJ, Oshima T, Attwell D. Glutamate release in severe brain ischaemia is mainly by reversed uptake. Nature. 2000;403(6767):316-21.

52. Revah O, Lasser-Katz E, Fleidervish IA, Gutnick MJ. The earliest neuronal responses to hypoxia in the neocortical circuit are glutamate-dependent. Neurobiol Dis. 2016;95:158-67.

53. Urbach A, Baum E, Braun F, Witte OW. Cortical spreading depolarization increases adult neurogenesis, and alters behavior and hippocampusdependent memory in mice. J Cereb Blood Flow Metab. 2017:37(5):1776-90.

54. Eikermann-Haerter K, Lee JH, Yuzawa I, Liu CH, Zhou Z, Shin HK, et al. Migraine mutations increase stroke vulnerability by facilitating ischemic depolarizations. Circulation. 2012;125(2):335-45.

55. Hossmann KA. Periinfarct depolarizations. Cerebrovasc Brain Metab Rev. 1996:8(3):195-208

56. Dirnagl U, Tanabe J, Pulsinelli W. Pre- and post-treatment with MK-801 but not pretreatment alone reduces neocortical damage after focal cerebral ischemia in the rat. Brain Res. 1990;527(1):62-8.

57. Hartings JA, Rolli ML, Lu XC, Tortella FC. Delayed secondary phase of periinfarct depolarizations after focal cerebral ischemia: relation to infarct growth and neuroprotection. J Neurosci. 2003:23(37):11602-10.

58. Reeker W, Werner C, Mollenberg O, Mielke L, Kochs E. High-dose S(+ )-ketamine improves neurological outcome following incomplete cerebral ischemia in rats. Can J Anaesth. 2000;47(6):572-8.

59. Reinhart KM, Shuttleworth CW. Ketamine reduces deleterious consequences of spreading depolarizations. Exp Neurol. 2018;305:121-8.

60. Dreier JP, Major S, Pannek HW, Woitzik J, Scheel M, Wiesenthal D, et al. Spreading convulsions, spreading depolarization and epileptogenesis in human cerebral cortex. Brain. 2012;135(Pt 1):259-75.

61. Dorandeu F, Baille V, Mikler J, Testylier G, Lallement G, Sawyer T, et al. Protective effects of $S+$ ketamine and atropine against lethality and brain damage during soman-induced status epilepticus in guinea-pigs. Toxicology. 2007;234(3):185-93

62. Holtkamp M. Pharmacotherapy for refractory and super-refractory status Epilepticus in adults. Drugs. 2018;78(3):307-26.

63. Milakara D, Grozea C, Dahlem M, Major S, Winkler MKL, Luckl J, et al. Simulation of spreading depolarization trajectories in cerebral cortex: correlation of velocity and susceptibility in patients with aneurysmal subarachnoid hemorrhage. Neurolmage Clinical. 2017;16:524-38.

64. Woitzik J, Hecht N, Pinczolits A, Sandow N, Major S, Winkler MK, et al. Propagation of cortical spreading depolarization in the human cortex after malignant stroke. Neurology. 2013;80(12):1095-102.

65. Santos E, Scholl M, Sanchez-Porras R, Dahlem MA, Silos H, Unterberg A, et al. Radial, spiral and reverberating waves of spreading depolarization occur in the gyrencephalic brain. Neuroimage. 2014;99:244-55.

66. Santos E, Sanchez-Porras R, Sakowitz OW, Dreier JP, Dahlem MA. Heterogeneous propagation of spreading depolarizations in the lissencephalic and gyrencephalic brain. J Cereb Blood Flow Metab. 2017: 271678X16689801.

67. Hartings JA, Li C, Hinzman JM, Shuttleworth CW, Ernst GL, Dreier JP, et al. Direct current electrocorticography for clinical neuromonitoring of spreading depolarizations. J Cereb Blood Flow Metab. 2017;37(5):1857-70.

\section{Publisher's Note}

Springer Nature remains neutral with regard to jurisdictional claims in published maps and institutional affiliations. 